\title{
Job satisfaction, engagement, and burnout in the population of orthopedic surgeon and neurosurgeon trainees in mainland China
}

\author{
${ }^{*} J i n l i$ Yu, MA, ${ }^{1,2}$ Fei Zou, MD, ${ }^{3}$ and Yirui Sun, MD, PhD ${ }^{4}$ \\ Departments of ${ }^{1}$ International Medical Education and Cooperation, ${ }^{3}$ Orthopedics, and ${ }^{4}$ Neurosurgery, Huashan Hospital, Fudan \\ University, Shanghai, People's Republic of China; and ${ }^{2 H a r v a r d ~ M e d i c a l ~ S c h o o l, ~ B o s t o n, ~ M a s s a c h u s e t t s ~}$
}

OBJECTIVE In China, orthopedics and neurosurgery are among the most desired majors for medical students. However, little is known about the working and living status of specialists in these two fields. This study was aimed at evaluating job satisfaction, engagement, and burnout in the population of Chinese orthopedist and neurosurgeon trainees.

METHODS A nationwide online survey was administered in mainland China. Questionnaires were answered anonymously. Job satisfaction, engagement, and burnout were assessed using the Job Descriptive Index, the Utrecht Work Engagement Scale, and the Maslach Burnout Inventory, respectively.

RESULTS Data were collected from 643 orthopedist trainees and 690 neurosurgeon trainees. Orthopedists and neurosurgeons showed no statistical difference in terms of age, sex, job titles, and preference for working in tertiary hospitals. Orthopedists had a higher marriage rate $(p<0.01)$, a lower divorce rate $(p=0.017)$, relatively shorter working hours ( $p$ $<0.01)$, and a higher annual income $(p=0.023)$ than neurosurgeons. Approximately $40 \%$ of respondents experienced workplace violence in the last 5 years. Less than $10 \%$ of respondents were satisfied with their pay, and over $70 \%$ would not encourage their offspring to become a doctor. Orthopedists were more satisfied with their careers than neurosurgeons $(p<0.01)$ and had a higher level of work engagement $(p<0.01)$. In addition, a higher proportion of orthopedists were burnt out $(p<0.01)$ than neurosurgeons, though the difference between the two groups was not significant $(p=$ 0.088). Multivariate regressions suggested that younger age ( $\leq 25$ years old), being a senior trainee, getting divorced, working in a regional hospital, long working hours ( $\geq 71 \mathrm{hrs} / \mathrm{wk})$, a low annual income $(<¥ 100,000)$, sleeping $<6$ hrs/day, and experience with workplace violence were significantly related to burnout for both groups.

CONCLUSIONS Chinese orthopedic surgical and neurosurgical trainees are under significant stress. Orthopedic surgeons showed relatively optimistic data in their assessments of job satisfaction, engagement, and burnout. This study may provide valuable information for orthopedic and neurosurgical candidates considering either specialty as a career. https://thejns.org/doi/abs/10.3171/2019.12.FOCUS19830

KEYWORDS orthopedics; neurosurgery; trainee; career choice; job satisfaction

$\mathrm{F}$ OR medical students and interns, choosing a specialty is one of the most challenging decisions they will have to make. Prior investigations have shown that nearly $80 \%$ of medical students consider surgical specialties as their foremost career interest and that orthopedics and neurosurgery are among the most popular and competitive subspecialties. . $^{12,15,18,23,26}$ However, because of the limited period of clerkships and mandatory rotations, the duration or breadth of exposure to either specialty is usually limited. ${ }^{3,6}$ Surveys have indicated that students who choose a career in surgical specialties are often influenced by hospital orientation, role models, and perceived career rewards such as prestige or job opportunities, whereas the actual working and living statuses as a specialist are rarely considered. . $^{12,19,21,26}$

In mainland China, orthopedics and neurosurgery have relatively short histories. However, both have made remarkable progress during the past decades. To date, China has over 11,000 registered orthopedists and a comparative number of neurosurgeons, composing the largest groups of orthopedic and neurosurgical specialists in the world. ${ }^{1,16,33,36}$ In addition to their growing number of members, the two specialties share other similarities. For example, the two specialties are male dominated in

ABBREVIATIONS DP = depersonalization; EE = emotional exhaustion; JDI = Job Descriptive Index; MBI = Maslach Burnout Inventory; PA = personal accomplishment; UWES = Utrecht Work Engagement Scale.

SUBMITTED October 30, 2019. ACCEPTED December 19, 2019.

INCLUDE WHEN CITING DOI: 10.3171/2019.12.FOCUS19830.

* J.Y. and F.Z. contributed equally to this study and share first authorship. 
China. Both require general surgical knowledge and skills and share crossovers in spinal diseases. In the public image, being an orthopedist or a neurosurgeon is associated with a good income and high prestige. Despite these general impressions, however, little is known about the actual working and living status of Chinese orthopedic and neurosurgical trainees. The only related investigation was conducted 10 years ago, in which the working environment of Chinese orthopedic surgeons was investigated. ${ }^{16}$ For neurosurgeons, there has been no such relevant report. Thus, to address such questions, a national survey was conducted to reveal the current status of orthopedic surgical and neurosurgical trainees in China. The survey contained questions about different aspects of these positions, assessing the demographic and practice characteristics, job satisfaction, work engagement, and professional burnout of respondents. To our knowledge, this is the first national assessment of Chinese orthopedic surgical and neurosurgical trainees. It is hoped that this study will provide valuable information for Chinese medical students and young talents during their career choice. It may also cast light on future studies to improve the well-being of Chinese surgical specialists.

\section{Methods \\ Study Design}

This study was approved by the Ethical Review Board of Huashan Hospital and was part of a national investigation on the working environment and well-being of Chinese physicians, which was registered and approved by the Chinese Clinical Trial Registry (ChiCTR1800014762). Between June 2017 and October 2018, under the support of the East Institution of China Academy of Information and Communications Technology, the official orthopedics continuing education platform AllinMD (www.allinmd. $\mathrm{cn}$ ), and the national neurosurgical continuing education platform "Neurosurgery News" (www.medtion.com), an online survey was conducted via both smartphone applications and website visitation. Orthopedic and neurosurgical trainees working in tertiary (level III) and regional (level II) hospitals were included in this study. Respondents were recruited from all Chinese provinces except Hong Kong, Macao, and Taiwan. Doctors were invited to complete the online questionnaires anonymously via the mailing list of the three platforms listed above and during national or local academic conferences via quick-response (QR) code scanning. Responding surgeons were further grouped into junior and senior trainees according to their year of training. Junior trainees were equivalent to year 1-3 residents in the US, and senior trainees were equivalent to year 4-5 residents and 6-year fellows in the US. Surgeons who did not complete all of the online surveys were excluded from this study. To avoid repeated participation, each internet protocol (IP) address was permitted to fill out the questionnaire only once.

\section{Questionnaire}

The survey questionnaire consisted of 147 closed-ended questions organized into four sections including demographic and practice characteristics, job satisfaction, work engagement, and professional burnout. Most questions were designed according to well-developed and standard scales (see below), though a few questions were developed by us. Details for each section are described as follows.

\section{Demographic and Practice Characteristics}

In the demographic and practice characteristics section, respondents were asked to provide details on their sex, marital and family status, training status, type of current employer, weekly working hours, annual income, and experience of workplace violence, as well as the respondent's willingness to encourage their offspring to become a doctor. Workplace violence referred to physical abuse or threat, mostly from patients or their relatives, that created a risk to the health and safety of an individual or multiple medical specialists. In this study, workplace violence was independent of sex and did not involve sexual harassment. This information was also clarified in the questionnaire.

\section{Job Satisfaction}

Job satisfaction was measured using an index of job satisfaction, the Job Descriptive Index (JDI), which contains five dimensions, namely, the work itself (22 items), pay (9 items), promotions (7 items), coworkers (11 items), and supervision (14 items). ${ }^{10,28}$ Each item was scored 3 for "yes" responses, 0 for "no" responses, and 1 for responses of "not sure," with negatively worded items being reversecoded (there was no scoring of 2 in this version of the JDI).$^{10,28}$ The overall JDI scores were calculated as the sum of all items, with the scores for promotion and pay being multiplied by 2 . A higher score indicates a higher level of satisfaction. The internal consistency of the questionnaire was measured by Cronbach's $\alpha$ values for the five dimensions as $0.89,0.94,0.88,0.90$, and 0.87 , respectively.

\section{Work Engagement}

A respondent's work engagement was measured using the 17-item Utrecht Work Engagement Scale (UWES). The UWES has three subscales: vigor (6 items), dedication (5 items), and absorption (6 items). Answers to the UWES questionnaire were rated using a 7-point Likert scale (0-6). The UWES overall score was calculated as the sum of all items. ${ }^{7,24,25}$ Higher scores indicated a higher level of work engagement. Cronbach's $\alpha$ value for the UWES questionnaire was 0.85 .

\section{Professional Burnout}

Professional burnout was measured using the Maslach Burnout Inventory (MBI), covering three dimensions: emotional exhaustion (EE; 9 items), depersonalization (DP; 5 items), and personal accomplishment (PA; 8 items). Answers to each question were scored according to the frequency with which a respondent encountered each situation on a 7-point scale from "never" (0 points) to "daily" (6 points). Scores for each dimension were further graded as high, medium, or low (high $\mathrm{EE} \geq 27$, low $\mathrm{EE} \leq 18$, high $\mathrm{DP} \geq 10$, low $\mathrm{DP} \leq 5$, high $\mathrm{PA} \geq 40$, low $\mathrm{PA} \leq 33$ ). A respondent would be considered burnt out if he or she had high scores in the EE or DP section. ${ }^{14,17,27}$ Cronbach's $\alpha$ values for each section were $0.91,0.90$, and 0.85 , respectively, showing good internal consistency. 
TABLE 1. Demographic and practice characteristics of respondents

\begin{tabular}{|c|c|c|c|c|c|}
\hline \multirow[b]{2}{*}{ Characteristic } & \multicolumn{2}{|c|}{$\begin{array}{l}\text { Orthopedist } \\
(n=643)\end{array}$} & \multicolumn{2}{|c|}{$\begin{array}{l}\text { Neurosurgeon } \\
(n=690)\end{array}$} & \multirow{2}{*}{$\begin{array}{c}\mathrm{p} \\
\text { Value }\end{array}$} \\
\hline & No. & $\%$ & No. & $\%$ & \\
\hline Male sex & 598 & 93.00 & 647 & 93.77 & 0.57 \\
\hline \multicolumn{6}{|l|}{ Age in yrs* } \\
\hline$\leq 25$ & 291 & 45.26 & 323 & 47.02 & 0.57 \\
\hline $26-30$ & 261 & 40.59 & 252 & 36.68 & 0.13 \\
\hline $31-35$ & 81 & 12.60 & 101 & 14.70 & 0.28 \\
\hline$>35$ & 10 & 1.56 & 11 & 1.6 & 0.99 \\
\hline \multicolumn{6}{|l|}{ Marital status } \\
\hline Married & 293 & 45.57 & 260 & 37.68 & $<0.01$ \\
\hline Unmarried & 340 & 52.88 & 404 & 58.55 & $<0.01$ \\
\hline Divorced & 10 & 1.56 & 26 & 3.77 & 0.017 \\
\hline \multicolumn{6}{|c|}{$\begin{array}{l}\text { No. of in-house children } \\
\text { (married respondents } \\
\text { only) }\end{array}$} \\
\hline 0 & 92 & 31.40 & 115 & 44.23 & $<0.01$ \\
\hline 1 & 171 & 58.36 & 127 & 48.85 & 0.027 \\
\hline$\geq 2$ & 30 & 10.24 & 18 & 6.92 & 0.177 \\
\hline \multicolumn{6}{|l|}{ Training status } \\
\hline Junior trainee & 391 & 60.81 & 452 & 65.51 & \multirow[t]{2}{*}{0.078} \\
\hline Senior traineeł & 252 & 39.19 & 238 & 34.49 & \\
\hline \multicolumn{6}{|c|}{ Type of current employer } \\
\hline Level III hospital & 487 & 75.74 & 518 & 75.07 & 0.78 \\
\hline Public hospital & 568 & 88.34 & 633 & 91.74 & 0.019 \\
\hline \multicolumn{6}{|l|}{ Working hrs per week } \\
\hline$\leq 40$ & 40 & 6.22 & 47 & 6.81 & 0.66 \\
\hline $41-55$ & 185 & 28.77 & 186 & 26.96 & 0.46 \\
\hline $56-70$ & 235 & 36.55 & 215 & 31.16 & 0.038 \\
\hline$\geq 71$ & 183 & 28.46 & 242 & 35.07 & $<0.01$ \\
\hline \multicolumn{6}{|c|}{ Annual income (in $¥ 10,000$ ) } \\
\hline$<6$ & 82 & 12.75 & 105 & 15.22 & 0.20 \\
\hline $6-10$ & 140 & 21.77 & 222 & 32.17 & $<0.01$ \\
\hline $11-15$ & 276 & 42.92 & 212 & 30.72 & $<0.01$ \\
\hline $16-20$ & 85 & 13.22 & 100 & 14.49 & 0.50 \\
\hline$>20$ & 60 & 9.33 & 51 & 7.39 & 0.20 \\
\hline \multicolumn{6}{|c|}{$\begin{array}{l}\text { Are you satisfied w/ the } \\
\text { income? }\end{array}$} \\
\hline Yes & 60 & 9.33 & 56 & 8.12 & 0.43 \\
\hline No & 388 & 60.34 & 423 & 61.30 & 0.72 \\
\hline Not sure & 195 & 30.33 & 211 & 30.58 & 0.92 \\
\hline \multicolumn{6}{|l|}{ Sleeping hrs per day } \\
\hline$<4$ & 10 & 1.56 & 18 & 2.61 & 0.25 \\
\hline $4-6$ & 227 & 35.30 & 240 & 34.78 & 0.84 \\
\hline $6-8$ & 401 & 62.36 & 421 & 61.01 & 0.61 \\
\hline$>8$ & 5 & 0.78 & 11 & 1.59 & 0.21 \\
\hline \multicolumn{6}{|c|}{$\begin{array}{l}\text { Experience or witness of } \\
\text { workplace violence in } \\
\text { last } 5 \text { yrs? }\end{array}$} \\
\hline Yes & 249 & 38.72 & 301 & 43.62 & 0.069 \\
\hline
\end{tabular}

» CONTINUED FROM PREVIOUS COLUMN

TABLE 1. Demographic and practice characteristics of respondents

\begin{tabular}{|c|c|c|c|c|c|}
\hline \multirow[b]{2}{*}{ Characteristic } & \multicolumn{2}{|c|}{$\begin{array}{l}\text { Orthopedist } \\
(n=643)\end{array}$} & \multicolumn{2}{|c|}{$\begin{array}{l}\text { Neurosurgeon } \\
(n=690)\end{array}$} & \multirow{2}{*}{$\begin{array}{c}p \\
\text { Value }\end{array}$} \\
\hline & No. & $\%$ & No. & $\%$ & \\
\hline \multicolumn{6}{|l|}{$\begin{array}{l}\text { Encouraging child to } \\
\text { become a doctor? }\end{array}$} \\
\hline Yes & 40 & 6.22 & 50 & 7.25 & 0.46 \\
\hline No & 473 & 73.56 & 493 & 71.45 & 0.39 \\
\hline Not sure & 130 & 20.22 & 147 & 21.30 & 0.63 \\
\hline \multicolumn{6}{|c|}{$\begin{array}{l}n=\text { number of respondents. } \\
\text { Boldface type indicates statistical significance. } \\
\text { * Data missing for } 3 \text { neurosurgeons. } \\
\text { † Junior trainees are equivalent to year } 1-3 \text { residents in the US. } \\
\text { † Senior trainees are equivalent to year } 4-5 \text { residents and } 6 \text {-year fellows in } \\
\text { the US. }\end{array}$} \\
\hline
\end{tabular}

\section{Statistical Analysis}

Statistical analysis was performed using Stata 14 (StataCorp LLC) and Excel 2013 (Microsoft Corp.). Continuous variables are expressed as the means \pm standard deviations. Categorical variables were presented as percentages. The Shapiro-Wilk test and F-test were performed for normality and homogeneity testing. The Wilcoxon rank-sum test, $\mathrm{t}$-test, and ANOVA were used for the quantitative data of independent samples. Univariate analyses of categorical data were conducted with chi-square and Fisher exact tests. Differences were considered statistically significant with a two-tailed $\mathrm{p}$ value $<0.05$.

\section{Results}

\section{Demographic and Practice Characteristics}

During the study period, a total of 680 orthopedists and 700 neurosurgeons were invited to participate in the survey. Six hundred forty-three orthopedists $(94.56 \%)$ and 690 (98.57\%) neurosurgeons completed the online questionnaire. Nonresponders and those who did not complete the questionnaire were not included in the final statistics.

The demographic and practice characteristics of all responding surgeons are listed in Table 1 . The mean age of respondents was $29.21 \pm 6.82$ years, with a male/female ratio of 14.15:1. For both specialties, males were the overwhelming majority, consisting of $93 \%$ and $93.77 \%$ of responding orthopedists and neurosurgeons, respectively ( $p$ $=0.57$ ). Orthopedists and neurosurgeons showed no statistical difference in terms of age and training status.

However, the survey did indicate several differences between the two groups of specialists. First, orthopedic surgeons had a higher marriage rate $(\mathrm{p}<0.01)$ and lower divorce rate $(\mathrm{p}=0.017)$. Among the married respondents (553 respondents total), more than half had at least one child (62.57\%: $36.35 \%$ orthopedists and $26.22 \%$ neurosurgeons), but a statistically higher proportion of neurosurgeons did not have children $(\mathrm{p}<0.01$; Table 1$)$. Second, while the majority of orthopedists and neurosur- 
TABLE 2. Job satisfaction as measured by the JDI

\begin{tabular}{|c|c|c|c|c|c|}
\hline \multirow[b]{2}{*}{ JDI } & \multicolumn{2}{|c|}{$\begin{array}{c}\text { Orthopedist } \\
(n=643)\end{array}$} & \multicolumn{2}{|c|}{$\begin{array}{l}\text { Neurosurgeon } \\
\quad(n=690)\end{array}$} & \multirow{2}{*}{$\begin{array}{c}p \\
\text { Value }\end{array}$} \\
\hline & Mean & SD & Mean & SD & \\
\hline Total score & 107.69 & 35.64 & 102.47 & 37.15 & $<0.01$ \\
\hline \multicolumn{6}{|l|}{ Subscales } \\
\hline Work itself & 25.95 & 11.16 & 24.67 & 11.94 & 0.043 \\
\hline Pay & 7.66 & 3.89 & 7.37 & 4.22 & 0.20 \\
\hline Promotions & 7.55 & 4.47 & 6.64 & 4.51 & $<0.01$ \\
\hline Supervision & 26.99 & 12.70 & 25.01 & 13.37 & $<0.01$ \\
\hline Coworkers & 24.30 & 9.89 & 24.75 & 10.67 & 0.43 \\
\hline
\end{tabular}

Boldface type indicates statistical significance.

geons worked in tertiary hospitals $(75.74 \%$ and $75.07 \%$, respectively, $\mathrm{p}=0.78$ ), a lower percentage of orthopedists served in public hospitals $(88.34 \%$ vs $91.74 \%, \mathrm{p}=$ $0.019)$. Third, the survey indicated that the orthopedic trainees on average worked significantly longer than the statutory 40 hours per week $(59.56 \pm 7.49 \mathrm{hrs} / \mathrm{wk})$, and the neurosurgeon trainees worked even longer $(63.42 \pm$ $8.22 \mathrm{hrs} / \mathrm{wk} ; \mathrm{p}<0.01)$. There were $35.07 \%$ of responding neurosurgeons working more than $71 \mathrm{hrs} / \mathrm{wk}$, which was higher than the proportion of $28.46 \%$ among orthopedic trainees $(\mathrm{p}<0.01)$. However, it seems that long working hours were not associated with high incomes. Surveyed orthopedic surgeons had slightly higher annual incomes than neurosurgeons (¥11.17 $\pm 6.02 \times 10^{4}$ [approximately US $\$ 16,000 \pm 860$ ] vs $¥ 10.46 \pm 5.35 \times 10^{4}$ [approximately US $\$ 15,000 \pm 770], p=0.023)$. The most significant difference lay in the proportions of individuals with an annual income between $¥ 6-10 \times 10^{4}$ and $¥ 11-15 \times 10^{4}$. It is worth noting that only $9.33 \%$ of orthopedists and $8.12 \%$ of neurosurgeons were satisfied with their income $(\mathrm{p}=$ 0.43 ). Our survey also indicated that a significant proportion of respondents $(38.72 \%$ of orthopedists and $43.62 \%$ of neurosurgeons, $\mathrm{p}=0.069$ ) experienced or witnessed workplace violence in the last 5 years. When asked if they would like their child to become a doctor, $73.56 \%$ of orthopedists and $71.45 \%$ of neurosurgeons $(p=0.39)$ said they would never consider it.

TABLE 3. Job engagement as measured by the UWES

\begin{tabular}{|c|c|c|c|c|c|}
\hline \multirow[b]{2}{*}{ UWES } & \multicolumn{2}{|c|}{$\begin{array}{c}\text { Orthopedist } \\
(n=643)\end{array}$} & \multicolumn{2}{|c|}{$\begin{array}{l}\text { Neurosurgeon } \\
(n=690)\end{array}$} & \multirow{2}{*}{$\begin{array}{c}\mathrm{p} \\
\text { Value }\end{array}$} \\
\hline & Mean & SD & Mean & SD & \\
\hline Total score & 67.39 & 21.67 & 62.41 & 26.09 & $<0.01$ \\
\hline \multicolumn{6}{|l|}{ Subscales } \\
\hline Vigor & 24.35 & 7.98 & 22.43 & 21.72 & $<0.01$ \\
\hline Dedication & 19.64 & 7.81 & 18.40 & 8.90 & $<0.01$ \\
\hline Absorption & 23.40 & 8.90 & 21.58 & 9.63 & $<0.01$ \\
\hline
\end{tabular}

Boldface type indicates statistical significance.
TABLE 4. Burnout as measured by the MBI

\begin{tabular}{|c|c|c|c|c|c|}
\hline \multirow[b]{2}{*}{ MBI } & \multicolumn{2}{|c|}{$\begin{array}{c}\text { Orthopedist } \\
(n=643)\end{array}$} & \multicolumn{2}{|c|}{$\begin{array}{l}\text { Neurosurgeon } \\
(n=690)\end{array}$} & \multirow{2}{*}{$\begin{array}{c}p \\
\text { Value }\end{array}$} \\
\hline & No. & $\%$ & No. & $\%$ & \\
\hline Burnout & 302 & 46.97 & 292 & 42.32 & 0.088 \\
\hline \multicolumn{6}{|l|}{ Subscales } \\
\hline \multicolumn{6}{|l|}{ EE } \\
\hline Low & 126 & 19.60 & 109 & 15.80 & 0.069 \\
\hline Intermediate & 225 & 34.99 & 335 & 48.55 & $<0.01$ \\
\hline High & 292 & 45.41 & 246 & 35.65 & $<0.01$ \\
\hline \multicolumn{6}{|l|}{ DP } \\
\hline Low & 261 & 40.59 & 274 & 39.71 & 0.74 \\
\hline Intermediate & 205 & 31.88 & 240 & 34.78 & 0.26 \\
\hline High & 177 & 27.53 & 176 & 25.51 & 0.40 \\
\hline \multicolumn{6}{|l|}{ PA } \\
\hline Low & 301 & 46.81 & 313 & 45.36 & 0.59 \\
\hline Intermediate & 321 & 49.92 & 324 & 46.96 & 0.28 \\
\hline High & 21 & 3.27 & 53 & 7.68 & $<0.01$ \\
\hline
\end{tabular}

Boldface type indicates statistical significance.

\section{Job Satisfaction}

Job satisfaction among the orthopedists and neurosurgeons was assessed using the JDI, and the results are summarized in Table 2. Overall, the mean total JDI score for surveyed orthopedists was $107.69 \pm 35.64$, which was statistically significantly higher than the $102.47 \pm 37.15$ among neurosurgeons $(\mathrm{p}<0.01)$. For the five JDI subscales, orthopedic surgeons scored higher on questions on the work itself, promotions, and supervision $(p=0.043, p$ $<0.01$, and $p<0.01$, respectively) but showed no significant difference in terms of pay and coworkers compared to neurosurgeons.

\section{Work Engagement}

Table 3 indicates the UWES scores of orthopedists and neurosurgeons on three different dimensions. Overall, the orthopedists scored significantly higher on the UWES assessment, indicating that they were more enthusiastic about their work than were neurosurgeons $(p<0.01)$. Moreover, on all three dimensions of the UWES (vigor, dedication, and absorption), orthopedists scored significantly higher than their neurosurgical colleagues $(\mathrm{p}<0.01)$, indicating that orthopedists had higher levels of work engagement.

\section{Burnout}

Professional burnout among responding orthopedic and neurosurgical surgeons was assessed using the MBI, and the results are summarized in Table 4. Overall, $46.97 \%$ of orthopedists and $42.32 \%$ of neurosurgeons were burnt out, though the difference between the two groups was not statistically significant. Orthopedists showed heightened $\mathrm{EE}(\mathrm{p}<0.01)$ and a lower rate of feeling a high sense of PA $(\mathrm{p}<0.01)$. There was no statistical difference in feelings of DP between the two groups.

To better illustrate the association between burnout and 
TABLE 5. Multivariate analysis of burnout

\begin{tabular}{|c|c|c|c|c|c|c|}
\hline \multirow[b]{2}{*}{ Variable } & \multicolumn{3}{|c|}{ Orthopedist $(n=643)$} & \multicolumn{3}{|c|}{ Neurosurgeon $(n=690)$} \\
\hline & OR & $95 \% \mathrm{Cl}$ & $p$ Value & OR & $95 \% \mathrm{Cl}$ & p Value \\
\hline \multicolumn{7}{|l|}{ Age in yrs } \\
\hline$\leq 25$ & 2.46 & $1.77-3.44$ & $<0.01$ & 1.31 & $1.07-1.77$ & 0.041 \\
\hline $26-35$ & 0.54 & $0.40-0.74$ & $<0.01$ & 1.06 & $0.78-1.46$ & 0.71 \\
\hline$>35$ & 0.53 & $0.30-0.94$ & 0.029 & 0.54 & $0.35-0.83$ & $<0.01$ \\
\hline \multicolumn{7}{|l|}{ Marital status } \\
\hline Married & 0.96 & $0.46-1.75$ & 0.38 & 0.56 & $0.38-0.82$ & $<0.01$ \\
\hline Single & 1.14 & $0.60-2.16$ & 0.75 & 1.2 & $0.79-1.83$ & 0.39 \\
\hline Divorced & 3.86 & $1.31-5.58$ & 0.021 & 8.02 & $2.73-23.56$ & $<0.01$ \\
\hline \multicolumn{7}{|c|}{ No. of children living in-house (married only) } \\
\hline 0 & 1.16 & $0.65-2.41$ & 0.18 & 0.61 & $0.33-1.13$ & 0.11 \\
\hline 1 & 0.48 & $0.33-0.68$ & $<0.01$ & 1.38 & $0.97-1.97$ & 0.069 \\
\hline$\geq 2$ & 1.51 & $1.04-2.22$ & 0.028 & 0.76 & $0.46-1.17$ & 0.12 \\
\hline \multicolumn{7}{|l|}{ Type of current employer } \\
\hline Level III hospital & 0.47 & $0.33-0.69$ & $<0.01$ & 0.62 & $0.44-0.88$ & $<0.01$ \\
\hline Level II hospital & 2.10 & $1.45-3.04$ & $<0.01$ & 1.61 & $1.14-2.28$ & $<0.01$ \\
\hline Public hospital & 2.71 & $1.58-4.64$ & $<0.01$ & 0.16 & $0.058-0.42$ & $<0.01$ \\
\hline Private hospital & 0.37 & $0.21-0.63$ & $<0.01$ & 6.39 & $2.39-17.12$ & $<0.01$ \\
\hline \multicolumn{7}{|l|}{ Training status } \\
\hline Junior trainee* & 1.12 & $0.85-1.51$ & 0.057 & 0.84 & $0.60-1.18$ & 0.32 \\
\hline Senior trainee† & 1.70 & $1.23-2.38$ & $<0.01$ & 1.55 & $1.14-2.12$ & $<0.01$ \\
\hline \multicolumn{7}{|l|}{ Working hrs per wk } \\
\hline$\leq 55$ & 0.62 & $0.45-0.86$ & $<0.01$ & 0.45 & $0.32-0.64$ & $<0.01$ \\
\hline $56-70$ & 1.13 & $0.82-1.56$ & 0.45 & 0.55 & $0.39-0.77$ & $<0.01$ \\
\hline$\geq 71$ & 2.24 & $1.58-3.18$ & $<0.01$ & 3.61 & $2.60-5.01$ & $<0.01$ \\
\hline \multicolumn{7}{|l|}{ Annual income (in $¥ 10,000$ ) } \\
\hline$<10$ & 2.10 & $1.51-2.93$ & $<0.01$ & 2.09 & $1.53-2.84$ & $<0.01$ \\
\hline $11-15$ & 1.18 & $0.86-1.61$ & 0.31 & 0.63 & $0.45-0.89$ & $<0.01$ \\
\hline$\geq 16$ & 0.28 & $0.18-0.42$ & $<0.01$ & 0.58 & $0.40-0.86$ & $<0.01$ \\
\hline \multicolumn{7}{|l|}{ Sleeping hrs per day } \\
\hline$<6$ & 1.48 & $1.08-2.04$ & 0.016 & 2.24 & $1.64-3.07$ & $<0.01$ \\
\hline$\geq 6$ & 0.67 & $0.48-0.93$ & 0.018 & 0.45 & $0.33-0.61$ & $<0.01$ \\
\hline \multicolumn{7}{|c|}{ Experience or witness workplace violence in last $5 \mathrm{yrs}$} \\
\hline Yes & 1.35 & $1.16-1.68$ & 0.021 & 1.76 & $1.15-2.14$ & $<0.01$ \\
\hline
\end{tabular}

personal or career characteristics, multivariate regression analyses were performed (Table 5). In general, younger age ( $\leq 25$ years old), being a senior trainee, getting divorced, working at a level II regional hospital, long working hours ( $\geq 71 \mathrm{hrs} / \mathrm{wk})$, low annual income $(<¥ 100,000$ [approximately US\$14,300]), sleeping $<6 \mathrm{hrs} /$ day, and the experience of workplace violence were significantly related to the incidence of burnout among both orthopedists and neurosurgeons. Having more than one child living inhouse strongly indicated the incidence of burnout among orthopedists (OR 1.51, 95\% CI 1.04-2.22, $\mathrm{p}=0.028$ ), but this relationship was not observed among neurosurgeons. Interestingly, orthopedists serving in public medical fa- cilities were more likely to be burnt out (OR 2.71, 95\% CI 1.58-4.64, p < 0.01), whereas neurosurgeons working in private hospitals were more likely to be burnt out (OR 6.39, 95\% CI 2.39-17.12, p < 0.01).

\section{Discussion}

Previous studies have indicated that, for medical students and interns who consider pursuing a career in orthopedics or neurosurgery, approximately two-thirds make their decision during their final years (clerkship years) of medical school, whereas about one-third decide before medical school acceptance. ${ }^{12,23,29}$ However, most medical 
students at this stage have little formal exposure to either orthopedics or neurosurgery. Their career choices are often influenced by hospital orientations and perceived career rewards rather than by any understanding of the true world of a surgical specialist. Moreover, although orthopedics and neurosurgery are still the most desirable professions, data from recent years have shown that applications for surgical posts from medical students are falling. This trend is noticed not only in the Western world but also in developing countries, including China. ${ }^{4,5,15,23,30,34}$ Several authors have discussed possible reasons for the trend. For example, it is suspected that a lack of exposure to surgery, concerns about work-life balance, and machismo in the surgical profession may prevent talented applicants from choosing orthopedics or neurosurgery as a career. ${ }^{2,3,12,22} \mathrm{In}$ fact, data from this national survey indicated that being orthopedic or neurosurgical surgeons in China is not easy. Trainees in both fields have long working hours, relatively low incomes, high risks of encountering workplace violence, and high rates of burnout. For neurosurgeons, the situation seems to be even worse in terms of lower job satisfaction and work engagement.

In addition to the above considerations, in mainland China, there may be additional reasons for the decreasing interest in surgical professions. Firstly, there is a shortage in the workforce. Although Chinese orthopedists and neurosurgeons may have consisted of the world's largest groups of specialists in both fields, $1,16,33,36$ the undeniable fact is that they are also taking care of 1.38 billion Chinese people, the largest population in the world. According to the World Federation of Neurosurgical Societies (WFNS), even if all registered Chinese neurosurgeons were active, the density of neurosurgeons per 100,000 population would be 0.806 , ranking 52 among 162 countries. ${ }^{33}$ Given the lack of data on the international orthopedic workforce, it is hard to make comparative calculations for orthopedists, yet the situation is supposed to be similar. Studies have shown that Chinese orthopedists and neurosurgeons often see more patients or perform more operations on a given day than their colleagues in many other countries. ${ }^{13}$ As a result, long working hours are common among Chinese orthopedic and neurosurgical surgeons and are significantly associated with a high incidence of career burnout (Tables 4 and 5).

Secondly, Chinese orthopedic and neurosurgical trainees face prolonged training programs and relatively low incomes. Since 2016, a reformed mandatory training program has been launched by the Chinese authority. This program requires young Chinese surgeons to complete an additional 2-4 years of standard specialist training on top of the 3 years of general residency training and the 7-8 years of the postgraduate program. Under this new regulation, a Chinese medical student cannot become a qualified surgical specialist before finishing all $12-15$ years of training. This policy reform is intended in good faith. It attempts to encourage Chinese doctors to become the world's leading practitioners. By enforcing the standard training program, the new policy is also aimed to reduce the gap between doctors in different regions. However, an inevitable consequence is that the timing of young specialists' qualifications, pay increases, and promotions has been significantly postponed. Our study indicated that the annual income of Chinese orthopedic and neurosurgical trainees is between US $\$ 15,000$ and US $\$ 16,000$. Although this amount is nearly 4.5 times that from $2007^{16}$ and 1.12 times the average wage of Chinese urban employees,$^{20}$ considering the average of more than 60 working hours per week and decades of pre-career training, Chinese orthopedic and neurosurgical trainees are significantly underpaid.

Thirdly, workplace violence is harming the specialty. In the past 2 decades, Chinese doctors, especially surgeons, have experienced a surge of workplace violence, which has garnered close attention from the world. ${ }^{11,32}$ In our study, over $40 \%$ of respondents encountered workplace violence in the last 5 years. The reasons for the increase in workplace violence are complex and may relate to what is perceived as excessively high or unnecessary medical expenses, uneven distribution of medical resources, and biased media coverage that fuels tension. Other authors have performed detailed analyses of the Chinese doctor-patient relationship, ,11,31,32,35,37 which is not in the scope of this paper; however, the damaged doctor-patient relationship has actually scared off numerous medical students and potential applicants. ${ }^{34}$

Finally, the high demand for research productivity could be the last straw for potential trainees. For orthopedic and neurosurgical trainees, research is important for their survival, growth, and expansion. In the last decade, the Chinese authorities have attached great importance to investment in scientific research. Gross domestic spending on research and experimental development in mainland China has grown from US\$78.7 billion in 2005 to US $\$ 317.8$ billion in 2014, second in the world after the US. ${ }^{38}$ During the same period, China contributed approximately $2.6 \%$ of orthopedic and $6.3 \%$ of neurosurgical articles in international journals, ranking fifth in the world. In addition, China is the only country among the top five producers (US, United Kingdom, Japan, Germany, and China) with substantial growth in research productivity. Statistics have shown that the Chinese share of orthopedic research in the world increased from $0.43 \%$ in 2004 to $4.26 \%$ in 2015. The neurosurgical publications contributed by Chinese authors have increased at a rate of $121.9 \% \pm 9.98 \%$ per year between 1996 and 2009. ${ }^{838}$ However, it should be noted that behind these figures are the great efforts made by Chinese orthopedic and neurosurgical surgeons. Another reality is that the Chinese authority has made first/ corresponding authorship and successful funding applications prerequisites for doctors' promotions at all levels. In some tertiary hospitals, good-quality publication has even become a prerequisite for postgraduate or internship applications. As a result, it is quite common to see Chinese orthopedic and neurosurgical trainees work late in laboratories or be busy with clinical research projects after a full day of operations and outpatient clinics.

This study has several limitations. First, selection bias may exist in terms of recruitment for the online survey. Individuals with low morale, severe burnout, or an intention to quit are less likely to complete a voluntary survey. Moreover, the number of female respondents to the survey was limited. This could be attributable to the fact that women are a small minority in surgical specialties. For 
many years, these fields have been male dominated, and the proportion of women choosing orthopedic or neurosurgical surgery as a career has not changed much.

\section{Conclusions}

Both Chinese orthopedic and neurosurgical trainees are under significant stress. Orthopedic trainees showed relatively optimistic data in their assessments of job satisfaction, engagement, and burnout. This study may provide valuable information for orthopedic and neurosurgical candidates considering either specialty as a career.

\section{Acknowledgments}

This work was supported by the Shanghai Municipal Science and Technology Commission project (16411955300, 18441903300), Shanghai Municipal Commission of Health and Family Planning project (201840063, 201801075), Major and Develop Project of Chinese Ministry of Science and Technology (2017ZX09304005), Public Medical Artificial Intelligence Training Platform of Shanghai Municipal Commission of Economy and Informatization (XX-RGZN-01-17-4684), National Natural Science Foundation of China (NSFC81601914), and Shanghai Minhang Nature Science Foundation project (2018MHZ007).

We thank Drs. Junyan Chen, Jian Yu, Jianping Song, and Jingjing Xia for supporting this study.

\section{References}

1. Ausman JI: The rise of Chinese neurosurgery and neurosurgery in the developing world, and scientific colonialism. Surg Neurol 67:323-325, 2007

2. Azizzadeh A, McCollum CH, Miller CC III, Holliday KM, Shilstone HC, Lucci A Jr: Factors influencing career choice among medical students interested in surgery. Curr Surg 60:210-213, 2003

3. Chen H, Hardacre JM, Martin C, Lillemoe KD: Do medical school surgical rotations influence subspecialty choice? J Surg Res 97:172-178, 2001

4. Cockerham WT, Cofer JB, Biderman MD, Lewis PL, Roe SM: Is there declining interest in general surgery training? Curr Surg 61:231-235, 2004

5. Dias MS, Sussman JS, Durham S, Iantosca MR: Perceived benefits and barriers to a career in pediatric neurosurgery: a survey of neurosurgical residents. J Neurosurg Pediatr 12:422-433, 2013

6. Dougherty PJ, Chen C, Zhang Y: CORR ${ }^{\circledR}$ CurriculumOrthopaedic Education: orthopaedic surgery education in China. Clin Orthop Relat Res 475:35-38, 2017

7. Fong TC, Ng SM: Measuring engagement at work: validation of the Chinese version of the Utrecht Work Engagement Scale. Int J Behav Med 19:391-397, 2012

8. Hauptman JS, Chow DS, Martin NA, Itagaki MW: Research productivity in neurosurgery: trends in globalization, scientific focus, and funding. J Neurosurg 115:1262-1272, 2011

9. Hesketh T, Wu D, Mao L, Ma N: Violence against doctors in China. BMJ 345:e5730, 2012

10. Hulin CL, Smith PC: A linear model of job satisfaction. J Appl Psychol 49:209-216, 1965

11. Jiang Y, Ying X, Kane S, Mukhopadhyay M, Qian X: Violence against doctors in China. Lancet 384:744-745, 2014 (Letter)

12. Johnson AL, Sharma J, Chinchilli VM, Emery SE, McCollister Evarts C, Floyd MW, et al: Why do medical students choose orthopaedics as a career? J Bone Joint Surg Am 94:e78, 2012

13. Kim TK: $\operatorname{CORR}^{\circledR}$ International-Asia-Pacific: how to live a happy life as an orthopaedic surgeon. Clin Orthop Relat Res 475:597-600, 2017

14. Klimo P Jr, DeCuypere M, Ragel BT, McCartney S, Couldwell WT, Boop FA: Career satisfaction and burnout among U.S. neurosurgeons: a feasibility and pilot study. World Neurosurg 80:e59-e68, 2013

15. Kolias AG, Trivedi RA: Enhancing the exposure of medical students to neurosurgery. Br J Neurosurg 27:706, 2013

16. Ma ZS, Wang L, Du GS, Wang L, Chen XJ: What is the work environment of orthopaedic surgeons in China? Clin Orthop Relat Res 472:3576-3580, 2014

17. McAbee JH, Ragel BT, McCartney S, Jones GM, Michael LM II, DeCuypere M, et al: Factors associated with career satisfaction and burnout among US neurosurgeons: results of a nationwide survey. J Neurosurg 123:161-173, 2015

18. Mehmood SI, Kumar A, Al-Binali A, Borleffs JC: Specialty preferences: trends and perceptions among Saudi undergraduate medical students. Med Teach 34 (Suppl 1):S51-S60, 2012

19. Musunuru S, Lewis B, Rikkers LF, Chen H: Effective surgical residents strongly influence medical students to pursue surgical careers. J Am Coll Surg 204:164-167, 2007

20. National Bureau of Statistics of China: [Employment and wages in China.] Beijing: NBS (http://data.stats.gov. cn/easyquery.htm?cn=C01) [Accessed January 12, 2020] (Chinese)

21. Nguyen SQ, Divino CM: Surgical residents as medical student mentors. Am J Surg 193:90-93, 2007

22. Peters K, Ryan M: Machismo in surgery is harming the specialty. BMJ 348:g3034, 2014

23. Saleh M: Attracting the top medical students to a career in neurosurgery. Br J Neurosurg 27:405, 2013

24. Schaufeli WB, Bakker AB: Job demands, job resources, and their relationship with burnout and engagement: a multisample study. J Organ Behav 25:293-315, 2004

25. Schaufeli WB, Salanova M, Gonzálezromá V, Bakker AB: The measurement of engagement and burnout: a two sample confirmatory factor analytic approach. J Happiness Stud 3:71-92, 2002

26. Scott IM, Matejcek AN, Gowans MC, Wright BJ, Brenneis FR: Choosing a career in surgery: factors that influence Canadian medical students' interest in pursuing a surgical career. Can J Surg 51:371-377, 2008

27. Shanafelt TD, Balch CM, Bechamps GJ, Russell T, Dyrbye L, Satele D, et al: Burnout and career satisfaction among American surgeons. Ann Surg 250:463-471, 2009

28. Smith PC, Kendall LM, Hulin CL: The Measurement of Satisfaction in Work and Retirement. Chicago: Rand McNally, 1969

29. Strelzow J, Petretta R, Broekhuyse HM: Factors affecting orthopedic residency selection: a cross-sectional survey. Can J Surg 60:186-191, 2017

30. Sun HY, Ko YM, Lee SW, Lee B, Kim JH: The application rate for urology specialty compared with other specialties from 2007 to 2014 in Korea: is it influenced by social interest manifested by internet trends? BMC Urol 18:65, 2018

31. Wang XQ, Wang XT, Zheng JJ: How to end violence against doctors in China. Lancet 380:647-648, 2012

32. Wang Y, Fang M, Wang Y: How to decrease violence against doctors in China? Int J Cardiol 211:66, 2016

33. World Federation of Neurosurgical Societies: Global Neurosurgical Workforce Map. WFNS.org (https://www. wfns.org/menu/61/global-neurosurgical-workforce-map) [Accessed January 10, 2020]

34. Wu LX, Qi L, Li Y: Challenges faced by young Chinese doctors. Lancet 387:1617, 2016

35. Yueju L: Violence against doctors in China. Lancet 384:745, 2014 (Letter)

36. Zhao JZ, Zhou LF, Zhou DB, Tang J, Zhang D: The status 
quo of neurosurgery in China. Neurosurgery 62:516-521, 2008

37. Zhao L, Zhang XY, Bai GY, Wang YG: Violence against doctors in China. Lancet 384:744, 2014 (Letter)

38. Zou Y, Li Q, Xu W: Scientific research output in orthopaedics from China and other top-ranking countries: a 10-year survey of the literature. BMJ Open 6:e011605, 2016

\section{Disclosures}

The authors report no conflict of interest concerning the materials or methods used in this study or the findings specified in this paper.

\section{Author Contributions}

Conception and design: Yu, Zou. Acquisition of data: Yu, Zou. Analysis and interpretation of data: Yu, Zou. Drafting the article: $\mathrm{Yu}$, Zou. Critically revising the article: Sun. Reviewed submitted version of manuscript: Sun. Approved the final version of the manuscript on behalf of all authors: Sun. Statistical analysis: Zou. Administrative/technical/material support: Sun. Study supervision: Sun.

\section{Correspondence}

Yirui Sun: Huashan Hospital, Fudan University, Shanghai, China. yirui.sun@live.cn. 